УДК 635.054:58:069.029

DOI 10.30679/2219-5335-2019-4-58-180-189

АНАТОМИЧЕСКИЕ ОСОБЕННОСТИ
ЛИСТЬЕВ ПРЕДСТАВИТЕЛЕЙ
РОДА WЕІGЕLА ТНUNВ.
УЧЕБНОГО БОТАНИЧЕСКОГО
САДА КУБАНСКОГО
ГОСУДАРСТВЕННОГО
УНИВЕРСИТЕТА

Клюкина Анна Васильевна магистрант

Криворотов Сергей Борисович, д-р биол. наук, профессор, проф. кафедры биологии и экологии

Федеральное государственное бюджетное образовательное учреждение высшего образования «Кубанский государственный университет», Краснодар, Россия

Целью данной работы является изучение видов и сортов декоративного красивоцветущего кустарника рода Weigela Thunb. в Учебном ботаническом саду Кубанского государственного университета для применения их в озеленении городских садов и парков, а также использования в ландшафтном дизайне частных территорий. Объектом исследования являются растения рода Вейгела (Weigela Thunb.), произрастающие в коллекции Учебного ботанического сада. Материалом для написания работы послужили полевые записи и дневники, фотографии, рисунки, гербарные образцы растений исследуемого рода. Изучена анатомическая структура листьев видов и сортов рода Weigela Thunb. Исследования проводились 2018-2019 гг. В процессе работы применяли методы ботанической микротехники. В статье приведена краткая морфологическая характеристика листьев растений изучаемого рода. Приводятся результаты изучения анатомии листьев представителей рода Weigela Thumb. Анализ анатомического строения листьев
UDC 635.054:58:069.029

DOI 10.30679/2219-5335-2019-4-58-180-189

\section{ANATOMICAL FEATURES OF LEAVES \\ OF REPRESENTATIVES \\ OF WEIGELA THUNB. OF TRAINING \\ BOTANICAL GARDEN \\ OF KUBAN STATE UNIVERSITY}

Klyukina Anna Vasilyevna
Master Student

Krivorotov Sergey Borisovich, Dr. Sci. Biol., Professor

Prof. of Biology and Ecology Department

\section{Federal State Budget \\ Educational Institution \\ of Higher Education \\ «Kuban State University», Krasnodar, Russia}

The purpose of this work is to study the species and varieties of ornamental flowering shrubs of the genus Weigela Thunb. in the Kuban State University Traning Botanical Garden for their use in the gardening of urban gardens and parks, as well as the use in landscape design of private territories. The object of the research is the plants of the Weigela genus (Weigela Thunb.), growing in the collection of Training Botanical Garden. The material for writing the work was field records and diaries, photographs, drawings, herbarium specimens of plants genus under study. The anatomical structure of species and varieties leaves of the genus Weigela Thunb was studied. The studies were conducted 2018-2019. In the process research, the botanical microtechnology was applied. The article presents a brief morphological characteristics of the leaves of the studied genus. The results of studying the anatomy of the representatives leaves of the genus Weigela Thumb. are presented. Analysis of the anatomical structure of the leaves of the genus Weigela Thunb. 
растений сортов рода Weigela Thunb. позволил выявить следующие особенности. Эпидермис листа наиболее развит у кустарников сорта 'Nana Variegata' и составляет 2,0 мкм. Максимальная толщина флоэмной части пучка составляет 3,1 мкм у данного сорта. Ксилема и столбчатый мезофилл лучше развиты у листьев растений сорта 'Nana Variegata', кроме того, листья вейгелы этого сорта отличаются большей толщиной губчатого мезофилла. Механическая ткань в жилках листа наиболее выражена у растений сортов 'Nana Variegata' и 'Dame Blanche'. Ширина просвета ксилемной части пучка у всех представителей примерно одинакова, однако по этому показателю выделяются сорта 'Caricature' и 'Rumba'.

Ключевые слова: ВИД, СОРТ, РОД WEIGELA THUNB., УЧЕБНЫЙ БОТАНИЧЕСКИЙ САД plant varieties revealed the following features. The leaf epidermis is most developed in the variety 'Nana Variegata' and is $2,0 \mathrm{mcm}$. The maximum thickness of the phloem part of the beam is $3,1 \mathrm{mcm}$ for this variety. Xylem and columnar mesophyll are better developed in the leaves of 'Nana Variegata' variety, as well as the Weigela leaves are distinguished by the thickness of a spongy mesophyll. Mechanical tissue in the veins of the leaf is most expressed in the varieties of 'Nana Variegata' and 'Dame Blanche'.

The distance width of the beam xylem part is approximately the same for all representatives, but the varieties of 'Caricature' and 'Rumba' are outstanding according to this indicators.

Key words: SPECIES, VARIETY, GENUS OF WEIGELA THUNB., TRANING BOTANICAL GARDEN

Введение. В современном мире, с его многочисленными проблемами урбанизированной среды, существенно возрастает значимость зелёных насаждений, среди которых ведущая роль принадлежит древесным растениям. Деревья и кустарники - становой хребет парков, садов и скверов, основа большинства типов зелёных насаждений [1-6]. Особенно велико значение древесных растений в южных регионах, где они обеспечивают столь необходимые тень и прохладу в жаркое время года [7].

В озеленении урбоэкосистем покрытосеменные древесные растения играют основную роль как в экологическом, так и декоративном аспекте [8]. В то же время эти растения наиболее подвержены воздействию природных и антропогенных факторов [9-11]. Вследствие этого формирование результативно функционирующих и вместе с тем долговечных древесных насаждений является одной из наиболее значимых задач, поставленных для улучшения экологической обстановки в городах и сёлах [12-14].

На сегодняшний день парки и скверы города Краснодара характеризуются ограниченным видовым составом декоративных древесных расте- 
ний [14-18]. Между тем, в ботанических садах интродуцирован ряд новых видов, которые отличаются высокими показателями декоративности и устойчивости к городским условиям и представляют большой интерес для введения в культуру. В их числе красиво цветущие кустарники рода вейгела (Weigela Thunb.) [19].

Объекты и методы исследований. Исследования проводились 2018-2019 гг. в Учебном ботаническом саду Кубанского государственного университета. В процессе работы применяли методы ботанической микротехники [20]. Материалом исследований служили листья изучаемых видов и сортов рода Weigela Thunb., произрастающих в Учебном ботаническом саду Кубанского государственного университета, фотографии, рисунки.

Обсуждение результатов. Для изучения количественноанатомических особенностей листьев были выбраны 6 сортов рода Weigela Thunb.: 'Nana Variegata', 'Alexandra', 'Dame Blanche', 'Ruby Doll', 'Caricature', 'Rumba'.

По возрасту эти сорта различаются: 'Dame Blanche' (1982 г.), 'Rumba' (2002 г.), 'Alexandra' (2010 г.), 'Ruby Doll' (2014 г.), 'Caricature' (2014 г.), 'Nana Variegata' (2016 г.).

Морфологическое описание листьев растений сортов рода Weigela Thunb.:

-'Nana Variegata'- листья простые, расположены супротивно, листовая пластина эллиптической формы, с пильчатым краем, 4-8 см длиной, зеленая с желтоватой каймой по краю листа;

-'Alexandra' - листья супротивно расположенные, широкоэллиптические, 5-10 см длиной, глянцевые, от бордового летом до темнофиолетового осенью цвета, мелко-зазубренные по краям;

-'Dame Blanche' - листья небольшие, узкояйцевидные, 4-7 см длиной, темно-зеленые; 
Плодоводство и виноградарство Юга России № 58(04), 2019 г.

-'Ruby Doll' - листья темно-зеленые 6-10 см длиной, эллиптические, опадают поздно, осенняя окраска невзрачная;

-'Caricature' - листья эллиптические, заострённые на верхушке, около 6-12 см длиной, сверху голые, снизу опушённые, ярко зеленые, с кремовой каймой. Середина листа растет быстрее, чем край, создавая при этом скрученную форму;

-'Rumba' - листья эллиптические, светло зеленые с бронзовопурпурным оттенком, длиной около 6-8 см.

Листья исследованных сортов Weigela Thunb. гипостоматические устьица располагаются только на нижней стороне листовой пластинки вровень с клетками эпидермиса. Устьица анамоцитного типа (каждое устьице окружено 4-5 клетками эпидермиса, не отличающимися по форме и размерам от других эпидермальных клеток). По морфологическим признакам листья растений не отличались, механические повреждения и пятна отсутствовали.

Анатомические исследования заключались в измерении тканей листа и сравнении их между собой, результаты приведены в таблице.

Анатомическое строение листа сортов рода Weigela Thunb.

\begin{tabular}{|c|c|c|c|c|c|c|c|c|}
\hline 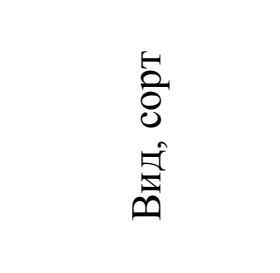 & 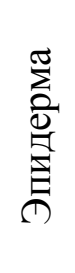 & 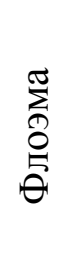 & 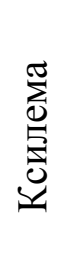 & 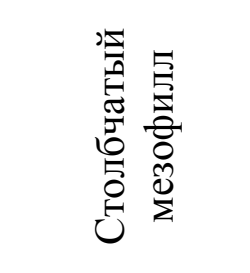 & 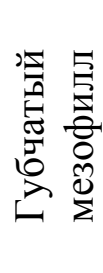 & 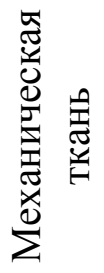 & 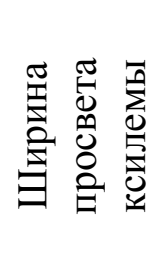 & 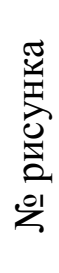 \\
\hline Nana Variegata & 2,0 & 3,1 & 4,3 & 2 ряда по 2,5 & 4,0 & 0,6 & 0,3 & 1 \\
\hline Alexandra & 1,5 & 2,0 & 1,4 & 2 ряда по 0,5 & 2,0 & 0,5 & 0,3 & 2 \\
\hline Dame Blanche & 1,3 & 2,0 & 1,6 & 2 ряда по 0,6 & 1,2 & 0,6 & 0,3 & 3 \\
\hline Ruby Doll & 1,6 & 1,7 & 3,3 & 2 ряда по 0,5 & 2,5 & 0,5 & 0,3 & 4 \\
\hline Caricature & 1,4 & 1,3 & 1,2 & 2 ряда по 0,5 & 1,5 & 0,3 & 0,2 & 5 \\
\hline Rumba & 1,2 & 1,3 & 1,6 & 2 ряда по 0,7 & 2,2 & 0,5 & 0,2 & 6 \\
\hline
\end{tabular}


У сорта 'Nana Variegata' в толще губчатой паренхимы листа расположены проводящие пучки. Имеются крупные пучки - до 2 мкм и мелкие, размер которых 0,5 мкм в диаметре. Между крупными пучками располагаются 1-2 мелких пучка. Среднее количество проводящих пучков на 1 мм² $^{2}$ составляет 7 шт. (см. рис. 1). В пучках ясно просматривается ксилема и флоэма, размер ксилемной части 4,3 мкм в диаметре.

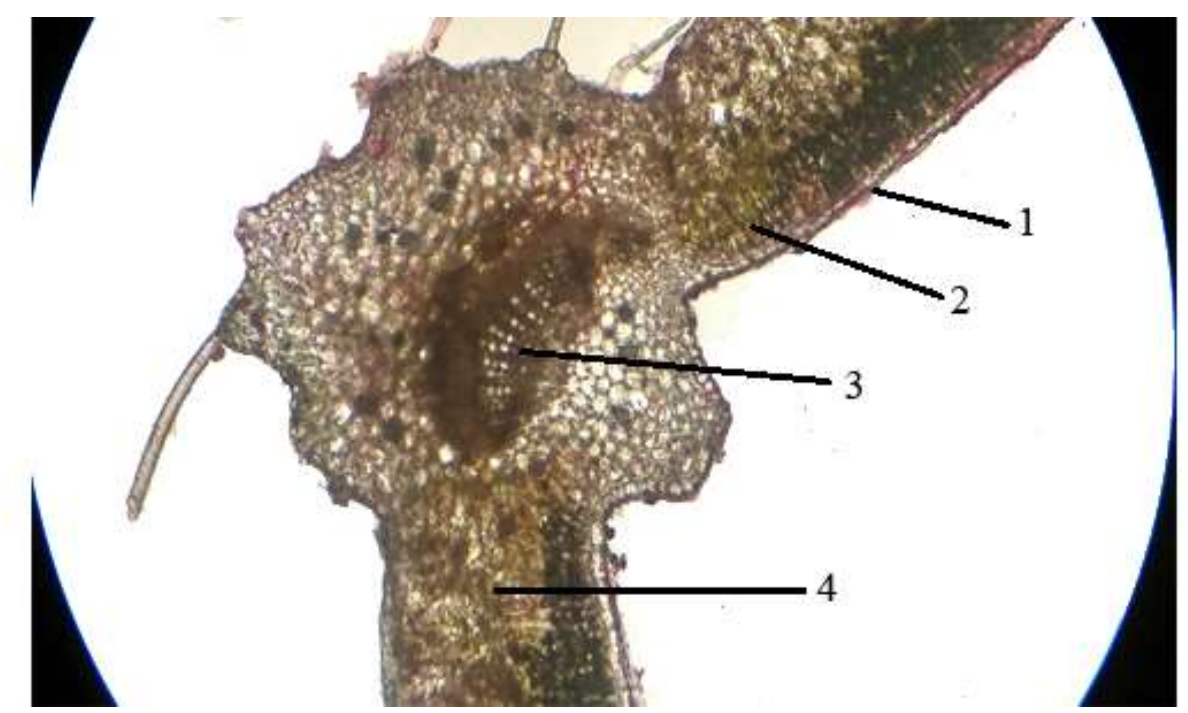

1 - эпидерма; 2 - столбчатый мезофилл; 3 - проводящие пучки; 4 - губчатый мезофилл Рис. 1. Анатомический срез листа 'NanaVariegata'

У сорта 'Alexandra' клетки губчатого мезофилла листа округлённые. В мезофилл погружены проводящие пучки, размер которых 0,3-0,5 мкм в диаметре, среднее количество на 1 мм² $^{2}$ составляет 9 шт. Внутри проводящих пучков отчётливо просматривается ксилема, размер клеток 0,5-1,4 мкм. Толщина эпидермы равна 1,5 мкм (см. рис. 2).

У сорта 'Dame Blanche' толщина эпидермиса составляет от 0,8 до 1,3 мкм. Основная часть листовой пластики приходится на долю мезофилла, который состоит из губчатой и ассимиляционной ткани. В неё погружены проводящие пучки от 0,1 до 0,3 мкм в диаметре, их среднее количество на $1 \mathrm{mм}^{2}$ составило 10 шт. Ксилемную часть пучка составляют клетки 0,8-1,6 мкм в диаметре (см. рис. 3). 


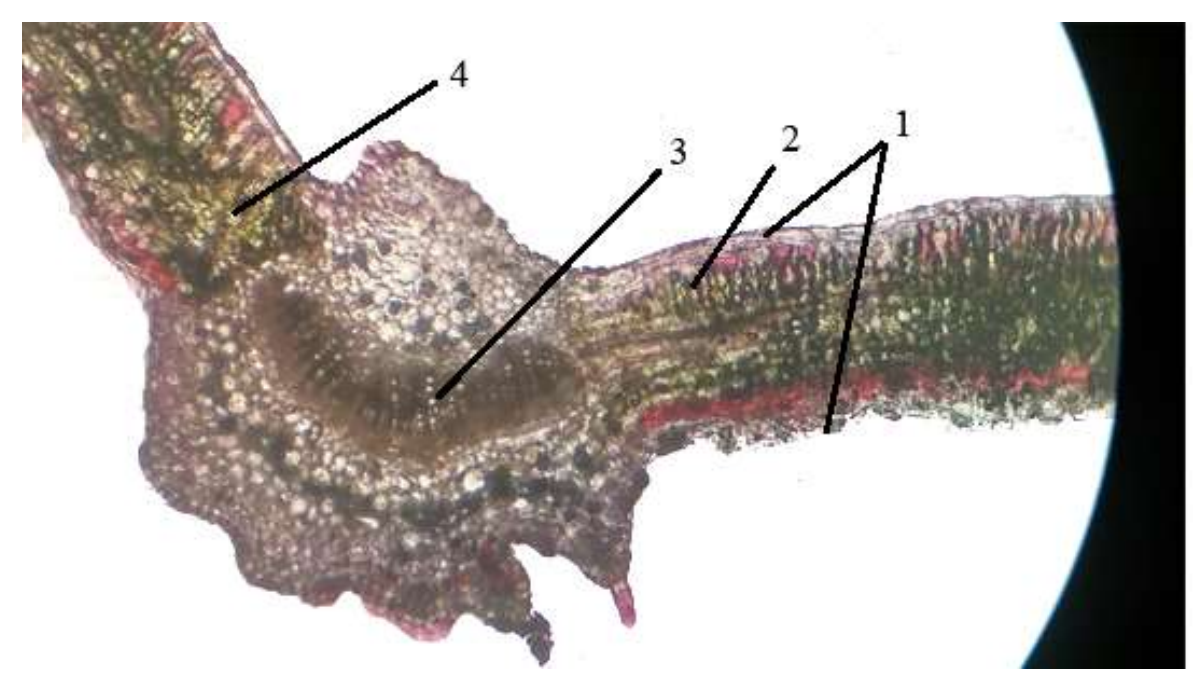

1 - эпидерма; 2 - столбчатый мезофилл; 3 - проводящие пучки; 4 - губчатый мезофилл Рис. 2. Анатомический срез листа 'Alexandra'

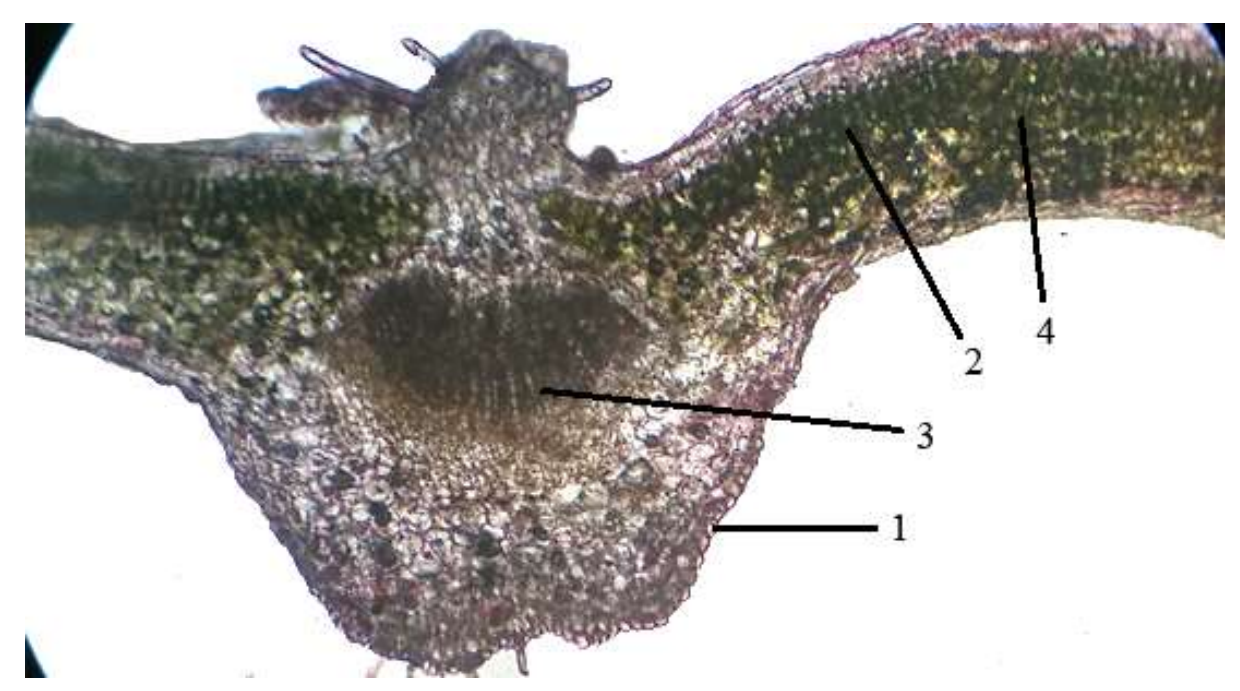

1 - эпидерма; 2 - столбчатый мезофилл; 3 - проводящие пучки; 4 - губчатый мезофилл Рис. 3. Анатомический срез листа 'Dame Blanche'

У copта 'Ruby Doll' в губчатой паренхиме расположены проводящие пучки диаметром от 1 до 2,5 мкм. Размер их варьирует от 0,1 до 0,3 мкм. Среднее количество проводящих пучков на $1 \mathrm{mм}^{2}$ составляет 4 шт. (см. рис. 4). В пучках просматривается ксилема и флоэма, размер ксилемной части 3,3 мкм в диаметре, флоэмной - до 1,7 мкм. 


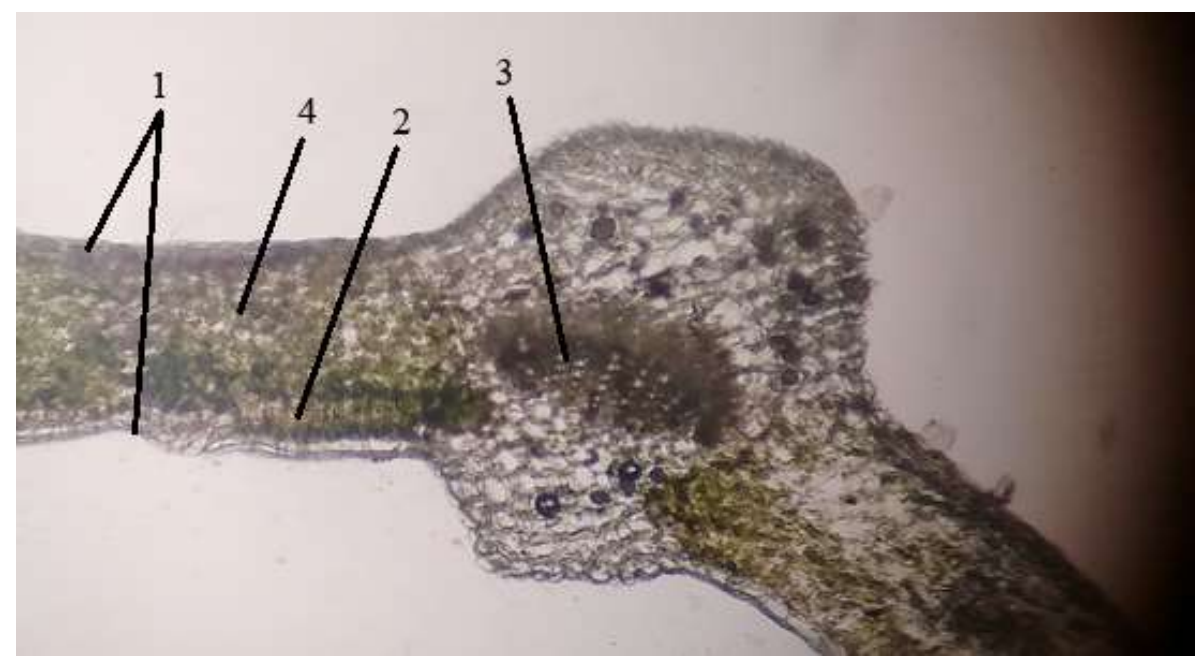

1 - эпидерма; 2 - столбчатый мезофилл; 3 - проводящие пучки; 4 - губчатый мезофилл Рис. 4. Анатомический срез листа 'Ruby Doll'

У сорта 'Caricature' все клетки губчатого мезофилла паренхимной формы. Размеры проводящих пучков 0,2 мкм в диаметре. Среднее их количество на $1 \mathrm{Mм}^{2}$ составило 8 шт. Столбчатый мезофилл располагается в два ряда, а размер одного ряда клеток составляет 0,5 мкм. Внутри проводящих пучков отчётливо просматривается ксилема, размер которой от 0,7 до 1,2 мкм. Толщина эпидермы равна 1,4 мкм (см. рис. 5).

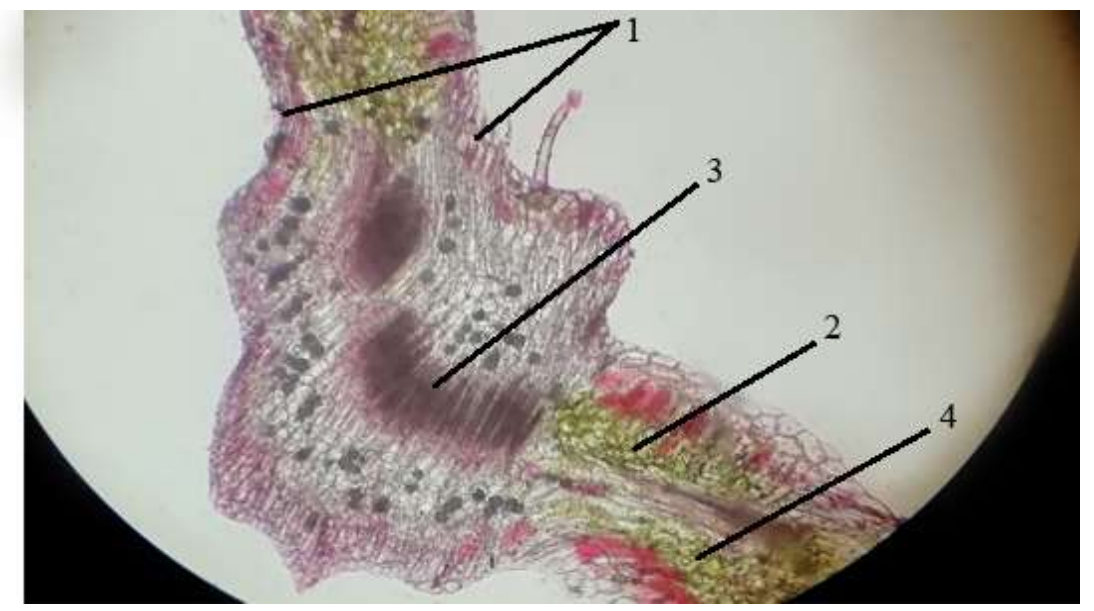

1- эпидерма; 2- столбчатый мезофилл; 3- проводящие пучки; 4- губчатый мезофилл Рис. 5. Анатомический срез листа 'Caricature'

У сорта 'Rumba' толщина эпидермиса составляет 1,2 мкм. Основная часть листовой пластинки приходится на долю мезофилла, который состоит из губчатой и столбчатой ассимиляционных тканей. Клетки столбчатой 
ткани крупные, по 0,7 мкм в диаметре, располагаются в 2 ряда. Губчатый мезофилл толщиной до 2,2 мкм преобладает, в него погружены проводящие пучки от 0,1 до 0,2 мкм в диаметре, их среднее количество на 1 мм² $^{2}$ составило 12 шт. Толщина ксилемной части пучка - 1,6 мкм (см. рис. 6).

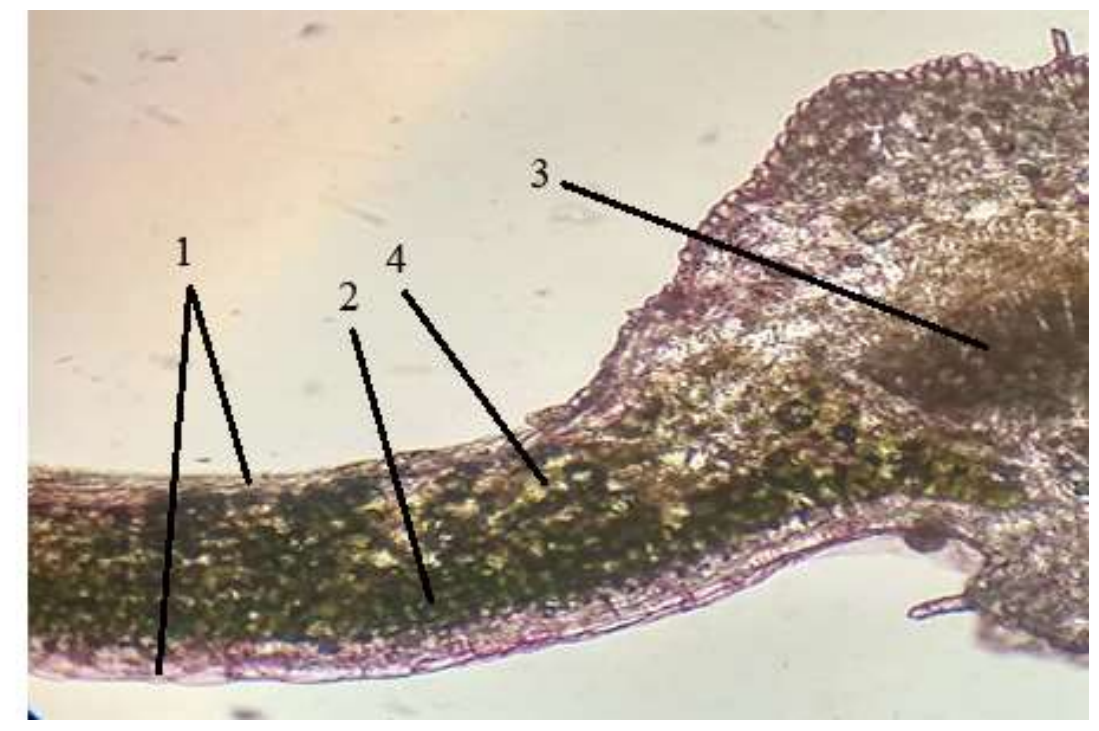

1- эпидерма; 2- столбчатый мезофилл; 3- проводящие пучки; 4- губчатый мезофилл

Рис. 6. Анатомический срез листа 'Rumba'

Заключение. Анализ анатомического строения листьев растений сортов рода Weigela Thunb. позволил выявить следующее: эпидермис листа наиболее развит у сорта 'Nana Variegata' и составляет 2,0 мкм. Максимальная толщина флоэмной части пучка составляет 3,1 мкм у сорта 'Nana Variegata'. У сортов 'Alexandra' и 'Dame Blanche' достигает 2,0 мкм.

Ксилема и столбчатый мезофилл лучше развиты у листьев сорта 'Nana Variegata'. Толщина ксилемной части пучка - 4,3 мкм, столбчатого мезофилла - 5 мкм. Листья вейгелы сорта 'Nana Variegata' отличаются толщиной губчатого мезофилла, составляющего 4,0 мкм. Механическая ткань в жилках листа наиболее выражена у сортов 'Nana Variegata' и 'Dame Blanche', составляет 0,6 мкм. Ширина просвета ксилемной части пучка у всех представителей примерно одинакова, но отличается у сортов 'Caricature', 'Rumba' и составляет 0,2 мкм. 


\section{Литература}

1. Аксёнова Н.А., Фролова Л.А. Деревья и кустарники для любительского садоводства и озеленения. М., 1989. 158 с.

2. Алексеев Ю.Е., Жмылев П.Ю., Карпухина Е.А. Деревья и кустарники. Энциклопедия природы России. М., 1997. 592 с.

3. Гусев Ю.Д. Деревья и кустарники СССР. Дикорастущие, культивируемые и перспективные для интродукции: в 6 т. Т. 6. / Под ред. С.Я. Соколова. М.; Л., 1962. $371 \mathrm{c}$.

4. Карпун Ю.Н. Субтропическая декоративная дендрология. Справочник. СПб., 2010. $580 \mathrm{c}$.

5. Покорны Я.М. Деревья вокруг нас. Прага, 1980. 192 с.

6. Былов В.Н. Основы сравнительной сортооценки декоративных растений // Интродукция и селекция цветочно-декоративных растений. М., 1978. С. 7-32.

7. Дьякова Т.Н. Декоративные деревья и кустарники: Новое в дизайне вашего сада. М., Колос, 2001. 360 с.

8. Жизнь растений. В 6-ти т. Цветковые растения. Т.5. Ч.1. / Под ред. А.Л. Тахтаджяна. М.: Просвещение, 1980. 430 с.

9. Горбачёв В.Н. Архитектурно-художественные компоненты озеленения городов: учеб. пособие для худож.-пром. ВУЗов и архит. фак. М.: Высшая школа, 1983. $207 \mathrm{c}$.

10. Приходько Г.Ю. Ландшафтное проектирование садовых и парковых объектов в условиях мегаполиса // Плодоводство и виноградарство Юга России, [Электронный ресурс]. Краснодар: СКЗНИИСиВ, 2013. № 20(2), С. 123-132. Режим доступа: http://www.journal.kubansad.ru/pdf/13/02/15.pdf

11. Михайлов С.М. Дизайн городской среды как вид синтетической деятельности. Исторический аспект // «Design-Review». Режим доступа: http://designreview.net/index.php?show=articles\&author_id=2

12. Liang X. Seeds of Weigela (Caprifoliaceae) from the Early Miocene of Weichang, China and the biogeographical history of the genus // Taxon, 2013. V. 62, P. 1009-1018.

13. Brookes J. Garden Masterclass / J. Brookes. New York: Darling Kindersley. 2002. 352 p. 15. Dickey P. Breaking Ground: Portraits of Ten Garden Designers / P. Dickey. New York: Artisan. 2003. 207 p.

14. Hayward G. Your House, Your Garden A Foolproof Approach to Garden Design / G. Hayward. New York: W.W. Norton. 2003. 192 p.

15. Strong R. Successful Small Gardens: New Designs for Time-Conscious Gardeners / R. Strong. New York: Rizzoli. 1995. 144 p.

16. Strong R. A Small Garden Designer`s Handbook / R. Strong. Boston: Little, Broun. 1989. 160 p.

17. Reid G. W. Landscape Graphics: Plan, Section and Perspective Drawing and Landscape Spaces / G. W. Reid. New York: Watson-Guptill. 2002. 216 p.

18. Batstone A. A Handbook for Garden Designers / A. Batstone, R. Batstone, K. Batstone. London: Ward Lock. 1996. 136 p.

19. Lambertini A. Meaning in Landscape Architecture \& Gardens. Four Essays, Four Commentaries-Marc Treib (ed.) // Journal on Landscape Architecture [Электронный pecypc]. 2014. № 9(1). 86-87. Режим доступа http://www.researchgate.net/journal/18626033_JoLAJournal_on_Landscape_Architecture.

20. Нагалевский В.Я. Ботаническая микротехника с элементами гистохимии. Краснодар, 1982. 29 с. 


\section{References}

1. Aksyonova N.A., Frolova L.A. Derev'ya i kustarniki dlya lyubitel'skogo sadovodstva i ozeleneniya. M., 1989. $158 \mathrm{~s}$.

2. Alekseev Yu.E., Zhmylev P.Yu., Karpuhina E.A. Derev'ya i kustarniki. Enciklopediya prirody Rossii. M., 1997. $592 \mathrm{s.}$

3. Gusev Yu.D. Derev'ya i kustarniki SSSR. Dikorastushchie, kul'tiviruemye i perspektivnye dlya introdukcii: v 6 t. T. 6. / Pod red. S.Ya. Sokolova. M.; L., 1962. $371 \mathrm{~s}$.

4. Karpun Yu.N. Subtropicheskaya dekorativnaya dendrologiya. Spravochnik. SPb., 2010. $580 \mathrm{~s}$.

5. Pokorny Ya.M. Derev'ya vokrug nas. Praga, 1980. $192 \mathrm{s.}$

6. Bylov V.N. Osnovy sravnitel'noj sortoocenki dekorativnyh rastenij // Introdukciya i selekciya cvetochno-dekorativnyh rastenij. M., 1978. S. 7-32.

7. D'yakova T.N. Dekorativnye derev'ya i kustarniki: Novoe v dizajne vashego sada. M., Kolos, 2001. 360 s.

8. Zhizn' rastenij. V 6-ti t. Cvetkovye rasteniya. T.5. Ch.1. / Pod red. A.L. Tahtadzhyana. M.: Prosveshchenie, 1980. $430 \mathrm{~s}$.

9. Gorbachyov V.N. Arhitekturno-hudozhestvennye komponenty ozeleneniya gorodov: ucheb. posobie dlya hudozh.-prom. VUZov i arhit. fak. M.: Vysshaya shkola, 1983. $207 \mathrm{~s}$.

10. Prihod'ko G.Yu. Landshaftnoe proektirovanie sadovyh i parkovyh ob"ektov v usloviyah megapolisa // Plodovodstvo i vinogradarstvo Yuga Rossii, [Elektronnyj resurs]. Krasnodar: SKZNIISiV, 2013. № 20(2), S. 123-132. Rezhim dostupa: http://www.journal.kubansad.ru/pdf/13/02/15.pdf

11. Mihajlov S.M. Dizajn gorodskoj sredy kak vid sinteticheskoj deyatel'nosti. Istoricheskij aspekt // «Design-Review». Rezhim dostupa: http://designreview.net/index.php?show=articles\&author_id $=2$

12. Liang X. Seeds of Weigela (Caprifoliaceae) from the Early Miocene of Weichang, China and the biogeographical history of the genus // Taxon, 2013. V. 62, P. 1009-1018.

13. Brookes J. Garden Masterclass / J. Brookes. New York: Darling Kindersley. 2002. 352 r. 15. Dickey P. Breaking Ground: Portraits of Ten Garden Designers / P. Dickey. New York: Artisan. 2003. 207 r.

14. Hayward G. Your House, Your Garden A Foolproof Approach to Garden Design / G. Hayward. New York: W.W. Norton. 2003. 192 p.

15. Strong R. Successful Small Gardens: New Designs for Time-Conscious Gardeners / R. Strong. New York: Rizzoli. 1995. 144 p.

16. Strong R. A Small Garden Designer`s Handbook / R. Strong. Boston: Little, Broun. 1989. 160 p.

17. Reid G. W. Landscape Graphics: Plan, Section and Perspective Drawing and Landscape Spaces / G. W. Reid. New York: Watson-Guptill. 2002. 216 r.

18. Batstone A. A Handbook for Garden Designers / A. Batstone, R. Batstone, K. Batstone. London: Ward Lock. 1996. 136 r.

19. Lambertini A. Meaning in Landscape Architecture \& Gardens. Four Essays, Four Commentaries-Marc Treib (ed.) // Journal on Landscape Architecture [Elektronnyj resurs]. 2014. № 9(1). 86-87. Rezhim dostupa http://www.researchgate.net/journal/18626033_JoLAJournal_on_Landscape_Architecture.

20. Nagalevskij V.Ya. Botanicheskaya mikrotekhnika s elementami gistohimii. Krasnodar, $1982.29 \mathrm{~s}$. 